\title{
Dry Powder Antibiotic Aerosol Product Development: Inhaled Therapy for Tuberculosis
}

\author{
ANTHONY J. HICKEY, ${ }^{1}$ AMIT MISRA, ${ }^{2}$ P. BERNARD FOURIE ${ }^{3}$ \\ ${ }^{1}$ Center for Aerosol and Nanomaterials Engineering, Research Triangle Institute, Research Triangle Park, North Carolina, 27709 \\ ${ }^{2}$ Central Drug Research Institute, Council of Scientific and Industrial Research, Sector 10, Janakipuram Extension, Lucknow, 226021 , \\ India \\ ${ }^{3}$ Department of Medical Microbiology, University of Pretoria, Pretoria, South Africa
}

\begin{abstract}
Inhaled therapies offer a unique approach to the treatment of tuberculosis (TB) using a relevant target organ system as a route of administration. The number of research reports on this topic has been increasing exponentially in the last decade but studies of clinical efficacy have been rare in recent times. The challenge is to take many research findings and translate them into a strategy for product development. Dry powder inhalers are the dominant drug product under consideration by those interested in the inhaled therapy for TB. A range of factors including candidate drug, formulation, device selection, drug product testing for proof of concept, and preclinical and clinical purposes all demand different considerations. The following review is intended to raise awareness of a growing body of evidence, suggesting that inhaled therapy for TB is possible and desirable. In addition, it is intended to outline key elements of the product-development activity for this particular application that has not been discussed elsewhere in the literature. Hopefully, this will encourage those with development expertise to seriously contemplate the steps required to bring such products forward.
\end{abstract}

Keywords: anti-infectives; drug delivery systems; factorial design; formulation; global health; multivariate analysis; powder technology; pulmonary drug delivery

\section{INTRODUCTION}

It has been proposed that inhaled therapies would potentially improve the current regimen of the treatment for tuberculosis (TB). ${ }^{1}$ Figure 1 depicts, by lighter and darker shading to indicate lower and higher concentrations, the advantages of high local doses and potentially circulating concentrations of the drug, achieved by oral and/or pulmonary delivery, sufficient to treat extrapulmonary infection. Research reports on this topic indicate successful outcomes in drug formulation, delivery, disposition, and efficacy in animal models of TB. ${ }^{2}$ However, a clear path is required for regulatory approval that applies general principles of pharmaceutical product development.

The current first-line agents for the treatment are delivered orally in very large doses: several hundreds of milligramsto-gram quantities daily. This includes isoniazid, rifampicin, ethambutol pyrazinamide, and streptomycin. ${ }^{3}$ Streptomycin is administered by injection. Of the second-line agents, some are delivered orally, for example, ethionamide, but others are delivered parenterally, for example, capreomycin. A few drugs have been approved recently for the treatment of multidrugresistant tuberculosis (MDR-TB), for example, bedaquiline (formerly TMC207), ${ }^{4}$ or are in the development, for example, PA-824. ${ }^{5}$ Poorly soluble, or poorly absorbed drugs are good candidates for pulmonary delivery by oropharyngeal inhalation. Among the established antituberculosis (anti-TB) drugs studied for pulmonary delivery are isoniazid, ${ }^{6}$ rifampicin, ${ }^{7-9}$

Correspondence to: Anthony Hickey (Telephone: +919-541-6771; Fax: +919541-6771; E-mail: ahickey@rti.org, ahickey@unc.edu) rifabutin, ${ }^{10}$ capreomycin,,${ }^{11-13}$ isoxyl,${ }^{14}$ PA- $824,{ }^{15,16}$ and clofazimine (CFM). ${ }^{17}$ Of the four principal first-line drugs, two, ${ }^{6}$ three, ${ }^{18}$ or all four (unpublished) have been incorporated in the same formulation intended for inhalation. A variety of unconventional agents targeting host responses rather than the bacterium have also been explored for anti-TB applications through pulmonary delivery. These include muramyl dipeptide for generalized immunostimulation of alveolar macrophages, ${ }^{19,20}$ small interfering RNA (siRNA) targeting the human chemokine XCL- $1^{21}$ or the pathogen-favoring cytokine TGF- $\beta,{ }^{22}$ siRNA to human suppressor of cytokine signaling (unpublished), nitric oxide donors, ${ }^{23}$ the antiprotozoal agent nitazoxanide, and the anticancer agent rapamycin (unpublished). The last two show anti-TB efficacy as a result of induction of autophagy in the infected macrophage. ${ }^{24}$

A considerable database is thus accumulating of novel formulations for drugs alone and in combination to treat pulmonary TB. ${ }^{7,25-32}$ Several of these papers go beyond formulation and present pharmacokinetic and/or tissue and bronchoalveolar lavage fluid data, indicating that therapeutic doses can be delivered as aerosols to the lungs. . $^{11,15,33-36}$ These doses may differ depending on the use of this route as a stand-alone or an adjunct therapy with respect to a particular drug. Recognizing: that monotherapy is not an option in TB treatment, inhaled formulations may either contain more than one drug if they are to stand alone or may be combined with peroral administration of additional drugs. A smaller number of papers extend to the evaluation of aerosol drug therapy in preclinical animal models of TB but these demonstrate that efficacy can be achieved by this route of administration for a variety of drugs and formulations. Unfortunately, few of these finding have led directly to clinical studies of any kind and none in recent times have 


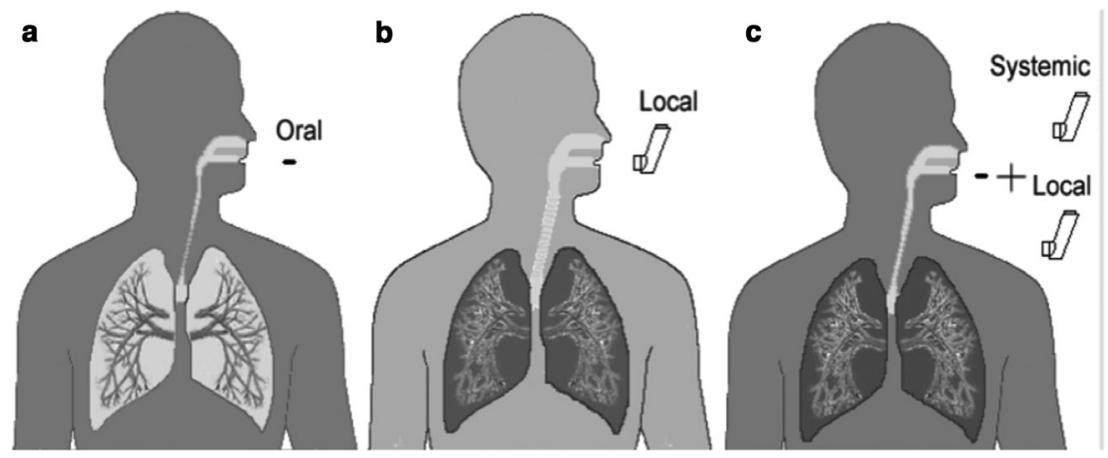

Figure 1. (a) Oral dosing achieves high systemic drug levels (by shading); (b) lung dosing achieves high local drug levels and; (c) combines the benefits of both routes and may be achieved by aerosol alone. From Ref.2.

addressed efficacy in humans. The ever-increasing interest in the development of inhaled drug therapies for TB raises the question of how to approach clinical development and to raise awareness of the potential of this approach.

\section{Clinical Experience with Inhaled Therapies for TB}

Human clinical experience with inhalation therapies for pulmonary TB, particularly in the form of clinical trials (CTs), is limited. A large volume of experimental work with inhalation therapies exist, in particular the German and Russian literature, over the past 60 years, but the treatments reported have not been developed as inhalation therapies for TB.

Interestingly, the urgency to address drug-resistant TB was the foundation of interest in inhaled aerosol therapy in the 1950 s, which parallels the current resurgence in interest in this route and means of administration. In a particularly noteworthy study reported in this period, 12 children with advanced TB were treated with aerosols of streptomycin. ${ }^{37}$ In this study, the disease in all except three children with atelectatic lesions responded to the therapy by healing; the most rapid response occurring in the children with the greatest amount of infiltration, consolidation, and cavitation. This is a remarkably positive outcome for an early study.

Recently, the advent of MDR-TB has revived an interest in the administration of drugs by inhalation, utilizing agents to treat TB or antibiotics otherwise administered by injection. The drug most studied in this way is kanamycin, an aminoglycoside.

In an early study, a subset of nine patients with sputumpositive pulmonary TB among 200 patients with bronchopulmonary suppurative disease, kanamycin aerosol therapy rendered four of the patients negative after 8 weeks of treatment. The treatment was well tolerated and practically free of side effects. ${ }^{14}$

More recently, five MDR-TB patients were treated at the Lemuel Shattuck Hospital in Boston with aerosolized kanamycin, in addition to receiving individualized conventional chemotherapy. The purpose of the intervention was adjunctive therapy. The goal was to use the inhaled kanamycin to achieve higher drug levels in lung tissues without any additional systemic toxicity, thereby accelerating cure. The drug was well tolerated and all five patients converted their sputum cultures within 60 days. $^{38}$

In 2001, Sacks et al. ${ }^{39}$ published a study of inhaled aminoglycosides (kanamycin and/or gentamicin) as a salvage therapy for patients in South Africa who had remained culture positive for 2 months or more despite appropriate conventional drugs. The population included seven patients with drug-susceptible TB and 12 with drug-resistant TB, including six who were HIV positive. These were all patients with unusually persistent positive sputum smears and cultures, with an average smear positivity of 96 days, but ranging up to 439 days. Control subjects included patients with only drug-susceptible infection. Despite selecting for persistent culture positivity, among patients with drug-susceptible isolates, two of three with cultures examined were negative within the first month of inhaled treatment. Among the 12 patients with drug-resistant isolates, only three had their cultures tested within 3 months of starting the inhaled aminoglycoside therapy, and all were negative. Overall, $68 \%$ of the patients converted their sputum from smear positive to negative while on therapy, including six of the seven with drug-susceptible TB and seven of the 12 with drug-resistant TB. Among the 13 who converted their sputum, the median time to conversion was 23 days, but the authors note that shorter times to conversion might have been observed had sputum samples been obtained earlier in the course of treatment.

Several other antibiotics with anti-TB activity, including levofloxacin, streptomycin, and neomycin, have been tried in inhaled form. Of these, the most recent work has been performed with a dry powder microparticle preparation of capreomycin. On the basis of novel large porous particle technology, ${ }^{40}$ capreomycin was formulated by spray drying into a dry powder composed of microparticles with an aerodynamic diameter of 1 $5 \mu \mathrm{m}$, which is suitable for delivery to the alveolar region of the lung. These powders, delivered directly to the lung, were demonstrated in a guinea pig model to lead to a higher local tissue concentration at significantly lower doses than those administered by injection, with good systemic absorption and efficacy against pulmonary TB. After gaining US Food and Drug Administration (FDA) approval, a phase I pharmacokinetics and maximum tolerated single-dose CT was successfully completed in healthy human volunteers in the USA. ${ }^{13}$

At least two recent papers proposed investigations on the pulmonary route of administration for clofazimine. ${ }^{17,41}$

Clofazimine, a substituted riminophenazine originally synthesized in 1954 as an anti-TB compound, has been abandoned in the treatment of TB since then, but the emergence of MDRTB has led to a renewed interest in the compound. CFM is listed by the WHO as a category- 5 drug, to be used for the treatment of MDR-TB when other drug choices are not applicable. Nevertheless, use of the drug is limited because of its adverse-effects 
profile, especially gastric intolerance, and remaining uncertainties as to the degree of efficacy in the target patient groups.

In a preliminary investigation, ${ }^{17}$ a dry powder inhaler comprising CFM in leucine microparticles (CFM-DPI) and native CFM were evaluated for activity against Mycobacterium tuberculosis in human-monocyte-derived macrophage cell cultures and in low-dose aerosol-infected mice. Both formulations resulted in $99 \%$ killing at $2.5 \mu \mathrm{g} / \mathrm{mL}$ in vitro. In mice, 480 and $720 \mu \mathrm{g}$ CFM-DPI inhaled twice per week over 4 weeks reduced colony-forming units in the lung by as much as $\log _{10} 2.6 ; 500 \mu \mathrm{g}$ oral CFM achieved $\log _{10} 0.7$ reduction.

Immunotherapy of resistant pulmonary TB was also investigated. In a recent systematic review of adjunctive therapy with interferon-gamma (IFN- $\gamma$ ) for the treatment of pulmonary TB, nine controlled CTs were analyzed that compared anti-TB drugs in combination with IFN- $\gamma$ with the same drugs alone in treating pulmonary TB. The meta-analysis showed statistical benefits on sputum-negative conversion as early as 1 month after the initiation of therapy. It was concluded that adjuvant therapy using IFN- $\gamma$, especially by aerosol, might be beneficial to TB patients, but large randomized controlled trials are needed for the further evaluation of its efficacy and safety considering the quality of the trials analyzed. ${ }^{42}$

Despite these advances, and a large opus of recently published experimental work in mice and guinea pigs indicating a potential for the enhanced efficacy of drugs, no anti-TB preparation has yet been indicated under a market authorization for direct administration to the lung in human subjects, either as adjunctive or substitution therapy. ${ }^{2}$

The only antibiotic currently marketed specifically for administration to the lung, but not for TB, is tobramycin. Inhalation of tobramycin solution in cystic fibrosis has been shown to contribute to reducing the lung-function decline and improving survival. However, the requirement for the aerosolization of these agents through nebulizers has been associated with increased treatment burden, reduced quality of life, and remaining a barrier to a broader uptake. The recent development of Tobramycin Inhalation Powder (TIP ${ }^{\mathrm{TM}}$ ), however, has brought the same benefits, but in a time-effective manner. Administered via the T-326 ${ }^{\mathrm{TM}}$ Inhaler (Novartis, San Carlos, CA) in four individual 28-mg capsules, TIP can be administered in a quarter of the time of traditional nebulizers and is inherently portable. In clinical studies, TIP has been shown to be safe, resulting in equivalent or superior reductions in Pseudomonas aeruginosa sputum density and producing similar improvements in the pulmonary function as does the aerosolized solution. ${ }^{43}$

\section{Clinical Trial Designs}

Issues around tolerability, pharmacokinetics, and drug clearance could be raised because of the novelty represented by dry powder inhalation of antibiotics. Consequently, the choice of drug for development as inhaled agents would preferably be established compounds used for the treatment of TB because of the advantage of drawing on preclinical and clinical experience gained during the development of the product.

The strategy for establishing proof-of-principle clinical data to pursue tolerability, dose, and efficacy might then be based on: (a) single, dose-escalation studies followed by multidose studies in normal volunteers; (b) identification of therapeutic dose relative to that of standard TB chemotherapy; and (c) identification of therapeutic dose of the inhaled agent relative to that of the reference parenteral or oral drug. The ideal approach to investigate the therapeutic dose and short-term tolerability would be to conduct an early bactericidal activity (EBA) study over 10-14 days, including a pharmacokinetics component. Most commonly, this would take the design of a prospective, dose-finding, open-label, placebo-controlled cohort study with four treatment groups comparing EBA and pharmacokinetic profiles following the administration of two inhaled dose strengths of the test agent, the reference drug, and standard oral anti-TB chemotherapy (whether first line or second line). The primary endpoint is the rate of fall in colony-forming units over the treatment period, with the primary efficacy endpoint being the relative difference in CFU counts between inhaled agent arms and the reference treatment arms at the end of the treatment period.

\section{REGULATORY CONSIDERATIONS}

Pharmaceutical product applications are submitted for government review and approval to organizations such as the FDA or the European Medicines Agency, two of the most prominent government approval bodies, for safety and quality review. Guidance documents are published by each of these government groups to allow the industry to prepare applications suitable for review. These agencies may utilize standards published by pharmacopoeias (United States or European Pharmacopoeias) to establish limits on certain quality and performance criteria such as aerodynamic particle size distribution (APSD) and dose delivery uniformity (DDU). The design of experiments to collect data sufficient to support the drug application dictates timelines and expenses incurred in the product development.

\section{NEW DRUG APPLICATION (NDA) OR ABBREVIATED NDA}

It should be noted that repurposing or delivering an existing approved drug by a new route of administration (the lungs) $)^{11,34}$ can be achieved through an abbreviated application-utilizing data generated for the original drug application, or on the basis by which it was approved. However, a new drug delivered by inhalation would be subject to regulations governing NDAs and would require a complete package for review by regulatory bodies. These facts will not be new or surprising to the reader but they are important to the inhaled therapy for TB because a range of old drugs is available for delivery by this route. With relatively little additional study or expense, these drugs, most of which have a half century or more of utility in large patient populations, delivered by a new route of administration, the lungs, may become important tools in the treatment of this increasingly insidious disease.

Most pharmaceutical scientists are familiar with a conventional dosage form the development plan and many may be aware of the unique aspects of inhaled product development. However, the majority of drugs for TB are delivered as oral dosage forms and a few are delivered as parenteral products. Important considerations for inhaled drug product development are not in the range of experience for most research scientists and clinicians treating TB. In this context, it is valuable to review the unique considerations that would apply to an inhaled dry powder dosage form containing an agent or agents to treat TB. This may have the added benefit of stimulating 


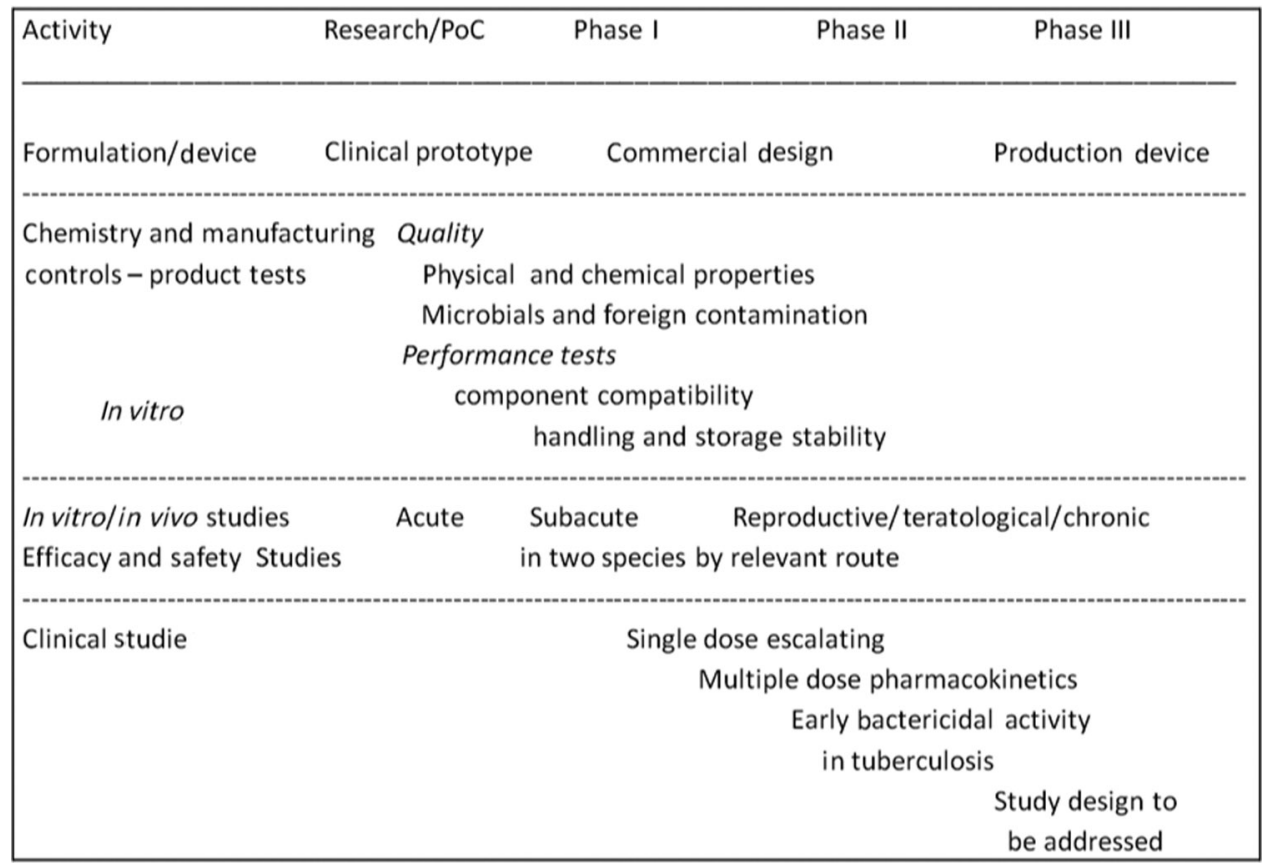

Figure 2. Schematic representation of product-development activities.

interest among those pharmaceutical scientists familiar with inhaled drug product development to bridge to the community of scientists currently working on TB.

\section{HYPOTHETICAL DEVELOPMENT PLAN}

Figure 2 shows a general development plan for a new drug delivered by inhalation for the TB therapy. On the basis of the factors outlined in previous sections and illustrated in Table 1 and Figure 3, it would be difficult to be more specific about the plan without considering key properties of the drug, drug formulation, metering system, device, strategy to enter phase I, and key endpoints for phases I and II studies.

\section{INHALED PRODUCTS}

Inhaled products are complex dosage forms consisting of drug formulation, metering system, and an aerosol-generation mechanism (usually the inhaler device), which require combined pharmaceutical science and engineering effort for successful development.
Figure 3 shows images of the components of a number of dry powder inhalers. Each of these components (formulation, metering system, and device) must be manufactured and assembled to specifications that ensure the final quality of the product and its performance. The drug product is assessed with regard to a number of important criteria that draw on further expertise to complete the development cycle including:

- Chemistry manufacturing and controls

- Regulatory pharmacology (Absorption Distribution Metablism Elimination (ADME) safety and efficacy) studies (preclinical-animals)

- Safety studies (preclinical-animals)

- Safety studies (phase I-healthy volunteers)

- Efficacy studies (phase II-patients)

- Efficacy studies (phase III-multicenter patient studies)

- Postapproval findings (phase IV-clinical monitoring)

Product development requires risk management. Approaches to address risk include the principles of Six Sigma, a system for establishing quality originally defined by the

Table 1. Dry Powder Inhaler Component Consideration

\begin{tabular}{|c|c|c|c|}
\hline Activity/Process & Feasibility/PoC & Clinical Batch & Production Scale \\
\hline Number of devices & Individual-tens & $100-1000 \mathrm{~s}$ & $1000-100,000 \mathrm{~s}^{*}$ \\
\hline Formulation & Bench scale & Pilot scale & Production scale \\
\hline Metering system & $\begin{array}{l}\text { From supplier (capsule or blister } \\
\text { Prototype if unique) }\end{array}$ & From supplier or at pilot scale & $\begin{array}{l}\text { From supplier or production scale } \\
\text { manufacture }\end{array}$ \\
\hline Filling of metering system & By hand & $\begin{array}{l}\text { By hand with some automation at } \\
\text { manufacturing site }\end{array}$ & Automated at manufacturing site \\
\hline Devices & $\begin{array}{l}\text { Individually crafted } \\
\text { stereolithography }\end{array}$ & Stereolithography initial tooling & $\begin{array}{l}\text { Plastics molding with commercial } \\
\text { tooling }\end{array}$ \\
\hline Assembly & By hand & By hand at manufacturing site & Automated at manufacturing site \\
\hline Analytical testing & Not regulated studies & cGLP, cGMP & cGLP, cGMP \\
\hline
\end{tabular}



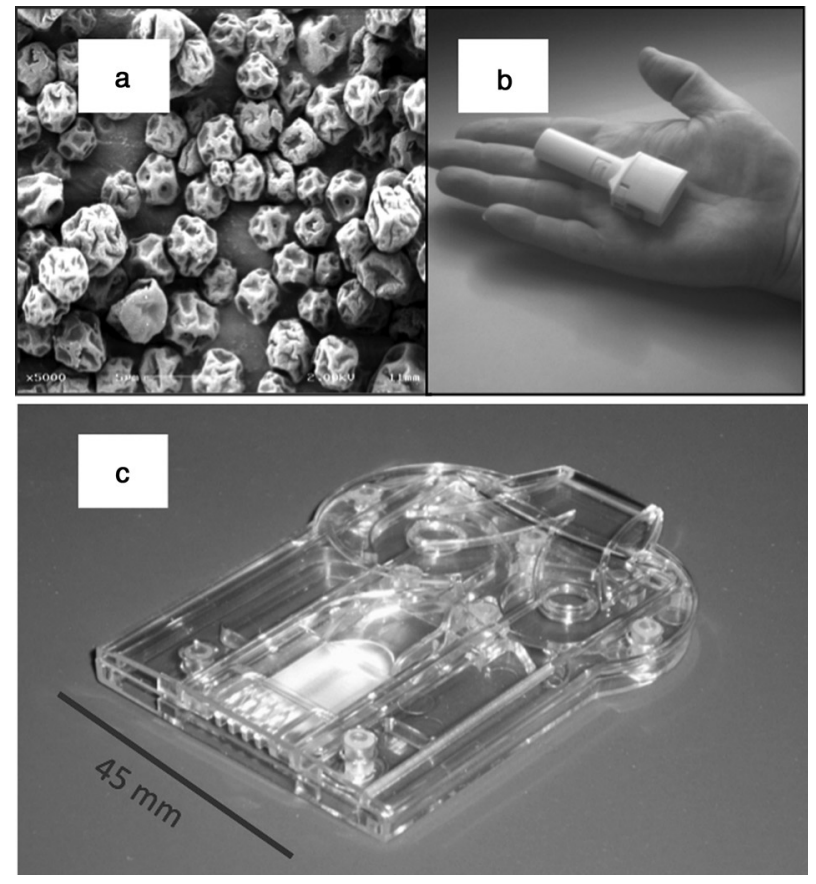

Figure 3. (a) Example formulation of capreomycin and leucine spraydried particles (collapsed hollow spheres); (b) cyclohaler capsule based device; and (c) Twincer, single-dose, disposable device.

electronics industry, and more recently in pharmaceutical development to include quality by design and process analytical technology, which in turn employ multivariate statistical controls. $^{44,45}$ The convergence of these methods allows risk mitigation through monitoring and control of the chronological series of processes under development. Table 1 illustrates a highlevel critical path assessment of the development of an inhaled product. Figure 4 shows a subset of activities that require attention to reduce the risk associated with each particular critical attribute. This representation illustrates the range of factors that impact on a critical attribute, which must, therefore, be controlled or monitored. Studies of inhaler performance generally focus on APSD and DDU, which directly contribute to effective lung delivery.

In addition to critical factors that impact performance attributes, there are other design features that require attention but are not on the critical path for the development. These factors would include ergonomic features to ensure that the patient uses the inhaler properly, shape and color considerations for the device, and instructions on use. Although not critical to the development program, their impact cannot be understated. For example, the size of the device is limited in terms of miniaturization by the dose of the drug/formulation and the required volume of the metering system. The color of the device is achieved by adding colorant to the plastic that has to be compatible with the drug. Ready availability of all selected components is required. Production-scale supply chain must be established for all components to avoid a delay in product launch. In addition, commercial manufacturing and assembly sites must be identified.

\section{Shelf Life}

It is an unfortunate epidemiological fact that the incidence and prevalence of TB is highest in regions classified as climatic zones III, IV, and IVb by the International Commission for Harmonization of Laboratory Data. Testing for the storage stability of the drug content and DPI performance characteristics under accelerated and long-term storage conditions is mandatorily carried out. There is still, however, a degree of ambiguity regarding testing the formulation alone under exposure to accelerated conditions. It is more pragmatic to subject the formulation-device combination to accelerated and long-term storage stability in the form of "drug product." It is difficult to demonstrate stability over 12 months if inhalable formulations are stored under conditions independent of the intended drug product packaging. Moreover, although the data on the storage

\section{SUMMARY OF PRODUCT VARIABLES}

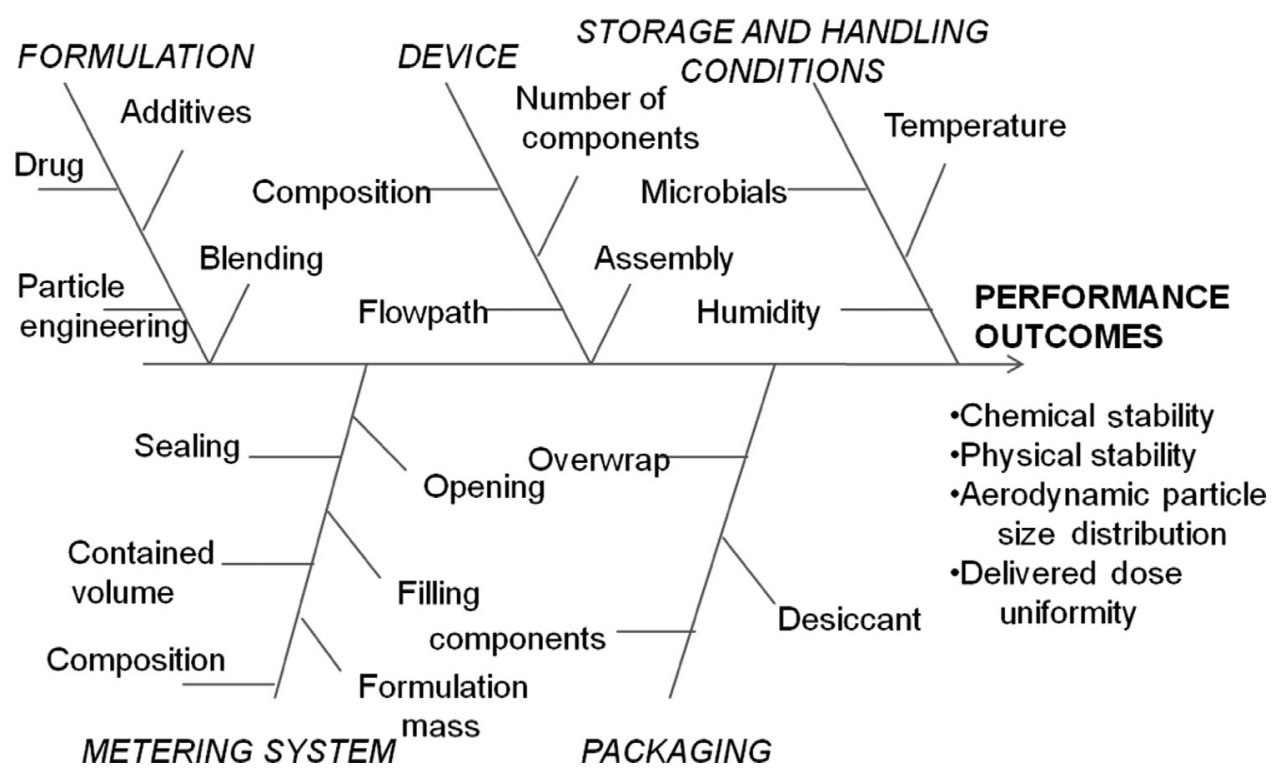

Figure 4. Dry powder inhaler performance considerations. 
of unpackaged formulation may have a value in product development, they will have little value for regulatory submission. Details of requirements for stability testing have been described previously. ${ }^{46}$

\section{BIOLOGICAL RISK MITIGATION}

\section{RISKS RELATED TO PRODUCT DEVELOPMENT AND INHALATION SAFETY ASSOCIATED WITH EXCIPIENTS}

From the point of view of product development, risks associated with excipient use are familiar to formulators, and relate to concerns of supply-chain integrity, product quality and uniformity, regulatory status and compatibility with manufacturing equipment, processes, and active substances. It is possible to minimize these risks by choosing to design a DPI containing anti-TB agents with the minimal use of excipient. When these must be used, for instance to improve the powder flow and aerosolization, or to prepare particles with targeting or sustained release functionality, it is still prudent to use minimal proportions to achieve desired specifications.

Biocompatibility concerns are more complex. Inhalation safety and toxicity must be established as an integral part of translation efforts directed at developing inhaled therapies for TB. It is important to execute these studies with a clear perception of hazards posed by common materials of the construction of pulmonary drug delivery systems in the context of pulmonary delivery.

The airways and lungs are immunologically active, having cellular and molecular components of mucosa-associated lymphoid tissue. Cells important for the mediation of innate and acquired immune responses observed in the bronchopulmonary mucosa include monocytes, macrophages, dendritic cells, neutrophils, mast cells, and lymphocytes. Although macrophages and dendritic cells are the chief antigen-presenting cells of this region, they also execute innate immune responses upon encountering and phagocytosing the inhaled material. Mast cells and neutrophils are more pertinent to innate responses elicited by the inhaled material. The variety or diversity of signaling and effector molecules observed in bronchial and alveolar mucosa indicates the putative degrees of sophistication and magnitudes of the immune response to the inhaled material. ${ }^{47}$

Adaptive immune responses are mediated through specific subpopulations of lymphocytes. Resident lymphocytes of the mouse lung include immunoglobulin (Ig) $\mathrm{M}^{+}$, but not $\operatorname{IgA}^{+}$ or $\mathrm{IgE}^{+} \mathrm{B}$ cells. About $80 \%$ of lung-resident plasma cells secrete IgA. CD4 ${ }^{+}$and $\mathrm{CD} 8^{+} \mathrm{T}$ cells and natural killer cells are present in larger numbers, and most of them have the $\alpha \beta$ configuration of the T-cell receptor (TCR). ${ }^{48}$ Cells with $\gamma \delta$ TCR are present in small numbers, but are a significant source of adverse responses to the inhaled material in view of their ability to mount innate responses against nonpeptide antigens such as lipids and carbohydrates, and also to recognize antigen presentation on nonclassical molecules of the major histocompatibility complex. ${ }^{49} \mathrm{CD} 4$ cell responses categorized as Th1 include interleukin (IL)-2, IL-12, IFN- $\gamma$, and tumor necrosis factor, and so forth, which have proinflammatory activities. Th2 cells produce IL-4, IL-10, IL-13, IL-25, and IL-33, which suppress Th1 responses. It is noteworthy that cytokine production and cross-talk initiates at the level of macrophages and dendritic cells. $^{50-52}$
Material depositing on the mucosal surface of the airways and lungs as phase-separated vesicles or particles is typically of a size range that is suitable for eliciting recognition and response by cells of the innate immune system. Drug delivery systems composed of active agents in combination with excipients of different kinds retain their phase-separated state for discrete time periods after deposition, and are, therefore, susceptible to immune recognition. Recognition need not necessarily result in stimulation, activation, or apoptosis of innate immune cells, as demonstrated in the case of rat macrophages encountering particles composed of poly(lactide-co-glycolide) versus poly(styrene).$^{8}$

\section{CONCLUSIONS}

Product development activities involve risk-mitigation strategies with respect to manufacture, shipping, storage, performance, clinical safety, and efficacy. These strategies involve both control and monitoring of processes, study designs, data collection, and handling to meet regulatory standards at a level sufficient for approval and to support commercialization. The cost and time expended on these activities are a key consideration if the patients are to benefit in a timely fashion and the product is to be therapeutically and commercially successful. Consideration of the full drug product development pathway requires urgent attention if new inhaled therapeutic approaches to the treatment of MDR-TB and extensively drug resitant TB (XDR-TB) are to be available for the prevention of a future global infectious disease crisis. It is hoped that the foregoing exposition, while necessarily an overview, elicits sufficient interest in the topic of inhaled TB therapies for practical steps to be taken to ensure that the full potential of this important strategy is addressed.

\section{ACKNOWLEDGMENTS}

Support from National Institute of Allergy and Infectious Disease for Dr. Hickey and from Open Source Drug Discovery and CSIR-BSC0112 for Dr. Misra is gratefully acknowledged. Images of Twincer device were kindly supplied by Professor Henderik Frijlink of Gröningen University, The Netherlands.

\section{REFERENCES}

1. Misra A, Hickey AJ, Rossi C, Borchard G, Terada H, Makino K, Fourie PB, Colombo P. 2011. Inhaled drug therapy for treatment of tuberculosis. Tuberculosis 91(1):71-81.

2. Muttil P, Wang C, Hickey AJ. 2009. Inhaled drug delivery for tuberculosis therapy. Pharm Res 26(11):2401-2416.

3. World Health Organization (WHO). 2009. Treatment of tuberculosis: Guidelines. 4th ed., Geneva: Switzerland: WHO.

4. Walsh S. 2012. FDA News Release. FDA Newsroom, Silver Spring, Maryland: US Department of Health and Human Services.

5. Dawson R, Diacon A. 2013. PA-824, moxifloxacin and pyrazinamide combination therapy for tuberculosis. Expert Opin Investig Drugs. 22:927-932

6. Sharma R, Saxena D, Dwivedi AK, Misra A. 2001. Inhalable microparticles containing drug combinations to target alveolar macrophages for treatment of pulmonary tuberculosis. Pharm Res 18(10):1405-1410.

7. O'Hara P, Hickey AJ. 2000. Respirable PLGA microspheres containing rifampicin for the treatment of tuberculosis: Manufacture and characterization. Pharm Res 17(8):955-961. 
8. Hirota K, Hasegawa T, Nakajima T, Inagawa H, Kohchi C, Soma G, Makino K, Terada H. 2010. Delivery of rifampicin-PLGA microspheres into alveolar macrophages is promising for treatment of tuberculosis. J Control Release 142(3):339-346.

9. Suarez S, O'Hara P, Kazantseva M, Newcomer CE, Hopfer R, McMurray DN, Hickey AJ. 2001. Airways delivery of rifampicin microparticles for the treatment of tuberculosis. J Antimicrob Chemother 48(3):431-434.

10. Muttil P, Kaur J, Kumar K, Yadav AB, Sharma R, Misra A.2007. Inhalable microparticles containing large payload of anti-tuberculosis drugs. Eur J Pharm Sci 32(2):140-150.

11. Garcia-Contreras L, Fiegel J, Telko MJ, Elbert K, Hawi A, Thomas M, VerBerkmoes J, Germishuizen WA, Fourie PB, Hickey AJ, Edwards D. 2007. Inhaled large porous particles of capreomycin for treatment of tuberculosis in a guinea pig model. Antimicrob Agents Chemother 51(8):2830-2836.

12. Garcia-Contreras L, Muttil P, Fallon JK, Kabadi M, Gerety R, Hickey AJ. 2012. Pharmacokinetics of sequential doses of capreomycin powder for inhalation in guinea pigs. Antimicrob Agents Chemother 56(5):2612-2618.

13. Dharmadhikari AS, Kabadi M, Gerety B, Hickey AJ, Fourie PB, Nardell E. 2013. Phase I, single-dose, dose-escalating study of inhaled dry powder capreomycin: A new approach to therapy of drug-resistant tuberculosis. Antimicrob Agents Chemother 57(6):2613-2619.

14. Wang C, Hickey AJ. 2010. Isoxyl aerosols for tuberculosis treatment: Preparation and characterization of particles. AAPS PharmSciTech 11(2):538-549.

15. Sung JC, Garcia-Contreras L, Verberkmoes JL, Peloquin CA, Elbert KJ, Hickey AJ, Edwards DA. 2009. Dry powder nitroimidazopyran antibiotic PA-824 aerosol for inhalation. Antimicrob Agents Chemother 53(4):1338-1343.

16. Garcia-Contreras L, Sung JC, Muttil P, Padilla D, Telko M, Verberkmoes JL, Elbert KJ, Hickey AJ, Edwards DA. 2010. Dry powder PA-824 aerosols for treatment of tuberculosis in guinea pigs. Antimicrob Agents Chemother 54(4):1436-1442.

17. Verma RK, Germishuizen WA, Motheo MP, Agrawal AK, Singh AK, Mohan M, Gupta P, Gupta UD, Cholo M, Anderson R, Fourie PB, Misra A. 2013. Inhaled microparticles containing clofazimine are efficacious in treatment of experimental tuberculosis in mice. Antimicrob Agents Chemother 57(2):1050-1052.

18. Pandey R, Sharma A, Zahoor A, Sharma S, Khuller GK, Prasad B. 2003. Poly (DL-lactide-co-glycolide) nanoparticle-based inhalable sustained drug delivery system for experimental tuberculosis. J Antimicrob Chemother 52(6):981-986.

19. Pettis RJ, Hall I, Costa D, Hickey AJ. 2000. Aerosol delivery of muramyl dipeptide to rodent lungs. AAPS PharmSci 2(3):E25.

20. Wang C, Muttil P, Lu D, Beltran-Torres AA, Garcia-Contreras L, Hickey AJ. 2009. Screening for potential adjuvants administered by the pulmonary route for tuberculosis vaccines. AAPS J 11(1):139147.

21. Rosas-Taraco AG, Higgins DM, Sanchez-Campillo J, Lee EJ, Orme IM, Gonzalez-Juarrero M. 2009. Intrapulmonary delivery of XCL1targeting small interfering RNA in mice chronically infected with Mycobacterium tuberculosis. Am J Respir Cell Mol Biol 41(2):136145.

22. Rosas-Taraco AG, Higgins DM, Sanchez-Campillo J, Lee EJ, Orme IM, Gonzalez-Juarrero M. 2011. Local pulmonary immunotherapy with siRNA targeting TGFbeta1 enhances antimicrobial capacity in Mycobacterium tuberculosis infected mice. Tuberculosis 91(1):98-106. 23. Verma RK, Agrawal AK, Singh AK, Mohan M, Gupta A, Gupta P, Gupta UD, Misra A. 2013. Inhalable microparticles of nitric oxide donors induce phagosome maturation and kill Mycobacterium tuberculosis. Tuberculosis 93(4):412-417.

24. Castillo EF, Dekonenko A, Arko-Mensah J, Mandell MA, Dupont N, Jiang S, Delgado-Vargas M, Timmins GS, Bhattacharya D, Yang H, Hutt J, Lyons CR, Dobos KM, Deretic V. 2012. Autophagy protects against active tuberculosis by suppressing bacterial burden and inflammation. Proc Natl Acad Sci U S A 109(46):E3168-3176.
25. Edwards DA, Ben-Jebria A, Langer R. 1998. Recent advances inpulmonary drug delivery using large, porous inhaled particles. J Appl Physiol 85(2):379-385.

26. Rijnders BJ, Cornelissen JJ, Slobbe L, Becker MJ, Doorduijn JK, Hop WC, Ruijgrok EJ, Lowenberg B, Vulto A, Lugtenburg PJ, de Marie S. 2008. Aerosolized liposomal amphotericin B for the prevention of invasive pulmonary aspergillosis during prolonged neutropenia: A randomized, placebo-controlled trial. Clin Infect Dis 46(9):1401-1408.

27. Khuller GK, Kapur M, Sharma S. 2004. Liposome technology for drug delivery against mycobacterial infections. Curr Pharm Des 10(26):3263-3274.

28. Vyas SP, Kannan ME, Jain S, Mishra V, Singh P. 2004. Design of liposomal aerosols for improved delivery of rifampicin to alveolar macrophages. Int J Pharm 269(1):37-49.

29. Astete CE, Sabliov CM. 2006. Synthesis and characterization of PLGA nanoparticles. J Biomater Sci Polym Ed 17(3):247-289.

30. Horn D, Rieger J. 2001. Organic nanoparticles in the aqueous phase-theory, experiment, and use. Angew Chem Int Ed Engl 40(23):4330-4361.

31. Sharma A, Sharma S, Khuller GK. 2004. Lectin-functionalized poly (lactide-co-glycolide) nanoparticles as oral/aerosolized antitubercular drug carriers for treatment of tuberculosis. J Antimicrob Chemother 54(4):761-766.

32. Pandey R, Khuller GK. 2004. Polymer based drug delivery systems for mycobacterial infections. Curr Drug Deliv 1(3):195-201.

33. Sung JC, Padilla DJ, Garcia-Contreras L, Verberkmoes JL, Durbin D, Peloquin CA, Elbert KJ, Hickey AJ, Edwards DA. 2009. Formulation and pharmacokinetics of self-assembled rifampicin nanoparticle systems for pulmonary delivery. Pharm Res 26(8):1847-1855.

34. Fiegel J, Garcia-Contreras L, Thomas M, VerBerkmoes J, Elbert K, Hickey A, Edwards D. 2008. Preparation and in vivo evaluation of a dry powder for inhalation of capreomycin. Pharm Res 25(4):805-811.

35. Verma RK, Kaur J, Kumar K, Yadav AB, Misra A. 2008. Intracellular time course, pharmacokinetics, and biodistribution of isoniazid and rifabutin following pulmonary delivery of inhalable microparticles to mice. Antimicrob Agents Chemother 52(9):3195-3201.

36. Verma RK, Mukker JK, Singh RS, Kumar K, Verma PR, Misra A. 2012. Partial biodistribution and pharmacokinetics of isoniazid and rifabutin following pulmonary delivery of inhalable microparticles to rhesus macaques. Mol Pharm 9(4):1011-1016.

37. Miller JB, Abramson HA, Ratner B. 1950. Aerosol streptomycin treatment of advanced pulmonary tuberculosis in children. Am J Dis Child 80(2):207-237.

38. Turner MT, Haskel R, McGowan K, Nardell E, Sabbag R. 1998. Inhaled kanamycin in the treatment of multidrug-resistant tuberculosis: A study of five patients. Infectious Diseases in Clinical Practice $7: 49-53$.

39. Sacks LV, Pendle S, Orlovic D, Andre M, Popara M, Moore G, Thonell L, Hurwitz S. 2001. Adjunctive salvage therapy with inhaled aminoglycosides for patients with persistent smear-positive pulmonary tuberculosis. Clin Infect Dis 32(1):44-49.

40. Edwards DA, Hanes J, Caponetti G, Hrkach J, Ben-Jebria A, Eskew ML, Mintzes J, Deaver D, Lotan N, Langer R. 1997. Large porous particles for pulmonary drug delivery. Science 276(5320):1868-1871.

41. Cholo MC, Steel HC, Fourie PB, Germishuizen WA, Anderson R. 2012. Clofazimine: Current status and future prospects. J Antimicrob Chemother 67(2):290-298.

42. Gao XF, Yang ZW, Li J. 2011. Adjunctive therapy with interferongamma for the treatment of pulmonary tuberculosis: A systematic review. Int J Infect Dis 15(9):e594-600.

43. Parkins MD, Elborn JS. 2011. Tobramycin inhalation powder: A novel drug delivery system for treating chronic Pseudomonas aeruginosa infection in cystic fibrosis. Expert Rev Respir Med 5(5):609-622.

44. Hickey AJ, Ganderton D. 2010. Pharmaceutical process engineering. 2nd ed. New York: Informa Health Care.

45. Hickey AJ, Smyth HDC. 2011. Pharmaco-Complexity: Non-linear phenomena and drug product development. New York: Springer/AAPS Press. 
46. Jones LD, McGlynn P, Bovet L, Hickey AJ. 2000. Stability concerns and approaches to analysis of pharmaceutical aerosols. Pharm Tech 24:40-54.

47. Suzuki T, Chow CW, Downey GP. 2008. Role of innate immune cells and their products in lung immunopathology. Int J Biochem Cell Biol 40(6-7):1348-1361.

48. Zhang J, Dong Z, Zhou R, Luo D, Wei H, Tian Z. 2005. Isolation of lymphocytes and their innate immune characterizations from liver, intestine, lung and uterus. Cell Mol Immunol 2(4):271280 .
49. Witherden DA, Havran WL. 2011. Molecular aspects of epithelial gammadelta T cell regulation. Trends Immunol 32(6):265-271.

50. Gonzalez-Juarrero M, O'Sullivan MP. 2011. Optimization of inhaled therapies for tuberculosis: The role of macrophages and dendritic cells. Tuberculosis 91(1):86-92.

51. Gordon S, Martinez FO. 2010. Alternative activation of macrophages: Mechanism and functions. Immunity 32(5):593-604.

52. Reljic R, Williams A, Ivanyi J. 2006. Mucosal immunotherapy of tuberculosis: Is there a value in passive IgA? Tuberculosis 86(3-4):179_ 190. 